\title{
Arousal from Sleep during Rapidly Developing Hypoxemia in Lambs
}

\author{
JAMES E. FEWELL AND SUSAN B. BAKER
}

Perinatal Research Laboratory, Department of Pediatrics and Physiology, University of Arkansas for Medical Sciences, Little Rock, Arkansas 72205

\begin{abstract}
Arousal is an important protective response that may prevent severe hypoxemia and death during sleep. However, very little is known about arousal from sleep in response to respiratory stimuli in newborns. Experiments were therefore done to investigate the arousal response from sleep to rapidly developing hypoxemia in eight lambs. Each lamb was anesthetized and instrumented for recordings of electrocorticogram, electrooculogram, nuchal and diaphragm electromyograms, and measurements of arterial hemoglobin oxygen saturation. A tracheotomy was done and a tracheostomy tube placed in the trachea so that the fraction of inspired oxygen could be changed quickly. No sooner than 3 days after surgery, measurements were made in quiet sleep and active sleep (AS) during 30-s control periods when the animals were breathing $21 \%$ oxygen and during experimental periods of hypoxemia when the animals were breathing either 10,5 , or $0 \%$ oxygen in nitrogen. During quiet sleep, arousal occurred at similar arterial hemoglobin oxygen saturations $\left(81 \pm 6 \%\right.$ on $10 \% \mathrm{O}_{2}, 80$ $\pm 5 \%$ on $5 \% \mathrm{O}_{2}$ and $83 \pm 5 \%$ on $0 \% \mathrm{O}_{2}$ ) suggesting that arousal was independent of the rate of change of arterial oxygen. However, during AS arousal occurred at different arterial hemoglobin oxygen saturations $(76 \pm 6 \%$ on $10 \%$ $\mathrm{O}_{2}, 55 \pm 11 \%$ on $5 \% \mathrm{O}_{2}$, and $44 \pm 17 \%$ on $0 \% \mathrm{O}_{2}$ ) suggesting that arousal was dependent on the rate of change of arterial oxygen. During some epochs of AS, electrocortical signs of cerebral hypoxia and primary apnea occurred before arousal. These data provide evidence that arousal from quiet sleep in response to hypoxemia occurs once an arousal threshold has been reached. However, during AS, arousal appears to follow an arousal latency once an arousal threshold has been reached. Furthermore, if the rate of change of oxygen is great enough during $\mathrm{AS}$, signs of cerebral hypoxia and primary apnea may precede arousal. These data would allow one to speculate that if the rate of change of arterial oxygen is great enough during apnea in AS, arousal may fail to occur before hypoxic cerebral depression and ultimately death ensue. (Pediatr Res 22: 471-477, 1987)
\end{abstract}

\section{Abbreviations}

ALTE, apparent life-threatening event

$\mathrm{SaO}_{2}$, arterial hemoglobin oxygen saturation

SIDS, sudden infant death syndrome

Received February 12, 1987; accepted May 19, 1987.

Correspondence and request for reprints James E. Fewell, Ph.D., Department of Obstetrics and Gynecology, University of Calgary, Health Sciences Centre, 3330 Hospital Drive N.W. Calgary, Alberta, T2N 4N1, Canada.

Supported by Public Health Service Grant, 1 ROI HL 34377. J.E.F. is an Established Investigator of the American Heart Association. S.B.B. was supported by a Research Training Fellowship Grant from the American Lung Association.
The arousal response, once characterized as "the forgotten response to respiratory stimuli (1)," is an important protective response that may prevent severe hypoxemia and death during sleep. Hypoxemia may occur during sleep in individuals with chronic lung disease [e.g. cystic fibrosis (2), bronchopulmonary dysplasia (3), asthma (4)] and/or during central or obstructive apnea. The usual respiratory response to hypoxemia is an increase in ventilation which tends to increase the alveolar and arterial oxygen tension. However, since the ventilatory response to hypoxemia is decreased during active sleep compared to quiet sleep in lambs (5) and calves (6) (i.e. species that develop ribcage paradox during active sleep) and the resumption of tidal ventilation during obstructive apnea is usually preceded by arousal (7-10), the arousal response may be the most important response to hypoxemia during sleep.

Despite the apparent importance of the arousal response from sleep to respiratory stimuli, little information is available in newborns concerning the arousal response per se, the mechanism of the arousal response or of factors that may impair the arousal response to respiratory stimuli. The purpose of the present experiments was to investigate the arousal response from sleep to rapidly developing hypoxemia in newborn lambs.

\section{METHODS}

Eight lambs ranging in age from 10 to 19 days were studied. Each lamb was separated from its ewe 1 to 3 days after birth and was housed in our laboratory in a plexiglass cage with continuous access to milk (Lamb Milk Replacer, Land O'Lakes, Inc., Fort Dodge, IA) via a teat mounted on one wall of the cage. The lambs were among other lambs, fed and slept ad libitum and soon became accustomed to the surroundings and laboratory personnel.

Surgical preparation. Each lamb underwent one operation prior to study. For surgery, each lamb was given atropine sulfate $(0.2 \mathrm{mg} / \mathrm{kg}$ subcutaneously) and ketamine $\mathrm{HCl}(10 \mathrm{mg} / \mathrm{kg}$ intramuscularly) and the trachea was intubated with a cuffed endotracheal tube. The cuff was inflated to a gas tight fit and anesthesia was maintained by ventilating the lamb's lungs with 1 to $3 \%$ isoflurane (Forane) in oxygen and nitrous oxide (3:1). An electrocardiogram and rectal temperature were monitored during surgery; body temperature was kept as near $39^{\circ} \mathrm{C}$ as possible with a heating pad.

The operation was done between 7 and 16 days of age. A double-lumen fiberoptic catheter oximeter (model U440 Opticath, Oximetrix, Inc., Moutain View, CA; $90 \%$ response to a step change in $\mathrm{SaO}_{2}$ within $5 \mathrm{~s}$ ) was inserted to the thoracic aorta via a femoral artery for continuous measurement of hemoglobin oxygen saturation and blood pressure. Electrodes for the following recordings were also implanted: electrocorticogram (recorded from electrodes placed through burr holes to lie over the parietal cortex), electrooculogram (recorded from electrodes placed at the inner and outer canthus of the right eye), nuchal electromy- 
ogram (recorded from electrodes placed in the dorsal cervical musculature), and diaphragm electromyogram (recorded from electrodes placed transabdominally into muscle fibers adjacent to the lateral margin of the central tendon of the right hemidiaphragm). A reference wire was sutured into the subcutaneous tissue of the scalp. The electrodes were made in our laboratory and were paired, Teflon-coated, multistranded stainless steel wires (AS 633, Cooner Wire Co., Chatsworth, CA); approximately $3 \mathrm{~mm}$ of the tip of each was bared and implanted. The proximal end of each wire was bared and soldered to the appropriate pin of an 18 pin electrical plug which was interfaced with four differential high impediance probes (7HIP5G, Grass Medical Instruments, Quincy, MA) during a study.

A tracheotomy was also performed and a fenestrated tracheostomy tube (Shiley, Inc., Irvine, CA) placed in the trachea. This tracheostomy tube allows one to select whether an animal breathes entirely through the opening of the tracheostomy tube (cuff inflated, inner cannula in place) or breathes entirely through its upper airway (cuff inflated, decannulation cannula in place). Following surgery, the decannulation cannula was inserted into the tracheostomy tube so that air flow during tidal respiration would be through the upper airway. The lambs were allowed to recover from surgery in a Shor-Line intensive care unit for small animals (Schroer Manufactoring Company, Kansas City, MO) and were then placed in a plexiglass study cage in our sleep laboratory but were not studied before the 3 rd postoperative day. The lambs received antibiotics (procaine penicillin G 100,000 $\mathrm{U} / \mathrm{kg}$; gentamicin sulfate $2 \mathrm{mg} / \mathrm{kg}$ for 5 days beginning on the day of surgery.

Conditions of observations. Our sleep laboratory consists of a large room $(12 \times 26 \mathrm{ft})$ which contains two sound attenuating chambers (W $4 \mathrm{ft}, \mathrm{H} 6.5 \mathrm{ft}, \mathrm{L} 6.5 \mathrm{ft}$ ). Each chamber has a oneway viewing mirror as well as a closed circuit video system to observe the lambs. Temperature, sound, and lighting can be precisely controlled in each chamber. Our recording equipment is kept in the room adjacent to the chamber. Prior to a study, a partition is placed in the cage to prevent the lamb from turning around once the catheter and electrode are connected. However, the lamb can still lie down, stand up, and feed ad libitum.

For a study, the vascular catheter is connected to a strain gauge manometer (Gould P23ID, Gould, Inc., Oxnard, CA) using rigid pressure monitoring tubing and the optical connector is connected to the optical module of the oximeter processor; the strain gauge manometer is placed at the approximate level of the heart when the animal is lying down. The inner cannula is placed into the tracheostomy tube and a breathing circuit (Neonatal Ventilator Circuit, model 5302, Intec Medical Inc., Blue Springs, MO) attached so that 10 liter/min of a known gas (i.e. $21,10,5$, or $0 \% \mathrm{O}_{2}$ ) can be passed by the tracheostomy tube. The 18-pin electrical plug is connected to the differential high impedance probes; a heavy duty cable connects the differential high impedance probes to A.C. preamplifiers (model 7P5 Wide Band A.C. EEG Pre-amplifier, Grass Medical Instruments, Quincy, MA) in the adjacent room. The electrophysiological signals are high-pass filtered using the $1 / 2$ amplitude low frequency response control on the A.C. preamplifiers (electrocorticogram $1.0 \mathrm{~Hz}$, electrooculogram $0.3 \mathrm{~Hz}$, and electromyograms $3 \mathrm{~Hz}$ ). The amplified activity from the electrocorticogram is full-wave rectified and then integrated (model 7P10 Polygraph Integrator, Grass Medical Instruments) to give a running record of the total accumulated area under the electrocortical waves (Fig. 1). The tracing writes out a ramp function, the slope of which is directly proportional to the ongoing input activity. Thus, the integrator output shows steep slopes when the electrocorticogram shows a high voltageslow wave pattern characteristic of quiet sleep. Low voltage-fast wave activity, characteristic of quiet wakefulness and active sleep, produces an integrator output with more gradual slopes.

The following electrophysiological criteria were used to define behavioral state once the animal was lying down (Fig. 2). During quiet wakefulness, the electrocorticogram shows a fast wave-low voltage pattern; there are occasional eye movements and there is
INTEGRATED ELECTROCORTICOGRAM
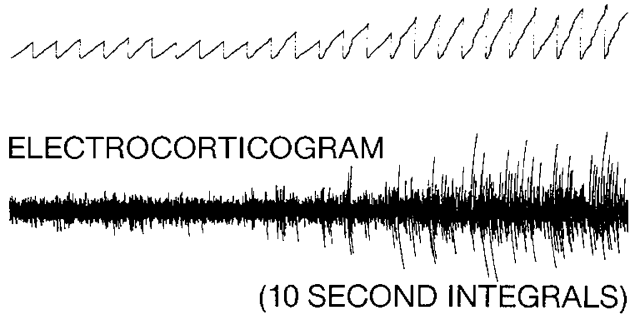

Fig. 1. Tracings showing raw and integrated recordings during lowvoltage and high-voltage electrocortical activity. The integrator was reset to baseline every $10 \mathrm{~s}$.

tonic activity on the nuchal electromyogram. During quiet sleep, the electrocorticogram shows a slow wave-high voltage pattern; there are no eye movements and there is tonic activity on the nuchal electromyogram. During active sleep, the electrocorticogram shows a fast wave-low voltage pattern; there are rapid eye movements on the electrooculogram; there is no activity on the nuchal electromyogram and there are occasional fast ear, facial, and limb twitches. Each lamb was allowed to cycle through at least one epoch of quiet sleep before the experiment actually began so that we could determine the amplitude of the integrated electrocortical activity and set strict criteria for defining quiet sleep.

The following electrophysiological criteria were used to define arousal from sleep. During quiet sleep, the point of arousal was determined by a change in the electrocorticogram from a high voltage-slow wave pattern to a low voltage-fast wave pattern (Fig. 3 ). During active sleep, the point of arousal was determined by a return of tonic activity on the nuchal electromyogram (Fig. 4).

Experimental protocol. During a study, systemic arterial blood pressure, hemoglobin oxygen saturation and the electrophysiological signals were recorded on a Grass model 7 polygraph (Grass Medical Instruments) and the lambs were monitored on a closed-circuit video system. Measurements were made during 30 -s control periods when the lambs were breathing $21 \%$ oxygen and during experimental periods of rapidly developing hypoxemia when the lambs were breathing either 10,5 , or $0 \%$ oxygen. At least two epochs of quiet sleep and active sleep were collected at each level of alveolar hypoxia in each animal. The inspired oxygen concentration used to produce rapidly developing hypoxemia was alternated on an hourly basis to avoid any sequence effects and the sequence was changed between animals $(e . g$. animal 1, 10-5-0-10-5\% etc.; animal 2, 0-10-5-0-10\% etc.; animal 3, 5-0-10-5-0\% etc.; etc.) Hypoxemia was terminated during an experimental period by changing the inspired oxygen concentration to $21 \%$ once the animal aroused from sleep. Because the mean epoch lengths of quiet sleep and active sleep of chronically instrumented lambs during this age range are 6 to $7 \mathrm{~min}$ and 3 to $4 \mathrm{~min}$, respectively (Johnson P, unpublished data), control measurements were made approximately 2 to 3 min after the lamb entered quiet sleep and approximately $30 \mathrm{sec}$ after the lamb entered active sleep. If an animal did not arouse within 2 min after being subjected to rapidly developing hypoxemia or if electrocortical signs of cerebral hypoxia occurred, the inspired oxygen concentration was changed back to $21 \%$. Experiments began between 0800 and $1000 \mathrm{~h}$ and continued until sufficient data were collected.

Statistical analysis. For every animal, we determined an average value for each variable during the control period and during the experimental period immediately preceding arousal (heart rate and blood pressure-five cardiac cycles; respiratory frequency and integrated diaphragm activity-five respiratory cycles if possible) for quiet sleep and active sleep; these values were used for statistical analysis. To analyze the data statistically, we performed a one-way analysis of variance for repeated measure of the same variable to determine if the fraction of inspired oxygen and thus the slope of $\mathrm{SaO}_{2}$ affected the time to arousal, the $\mathrm{SaO}_{2}$ at arousal 


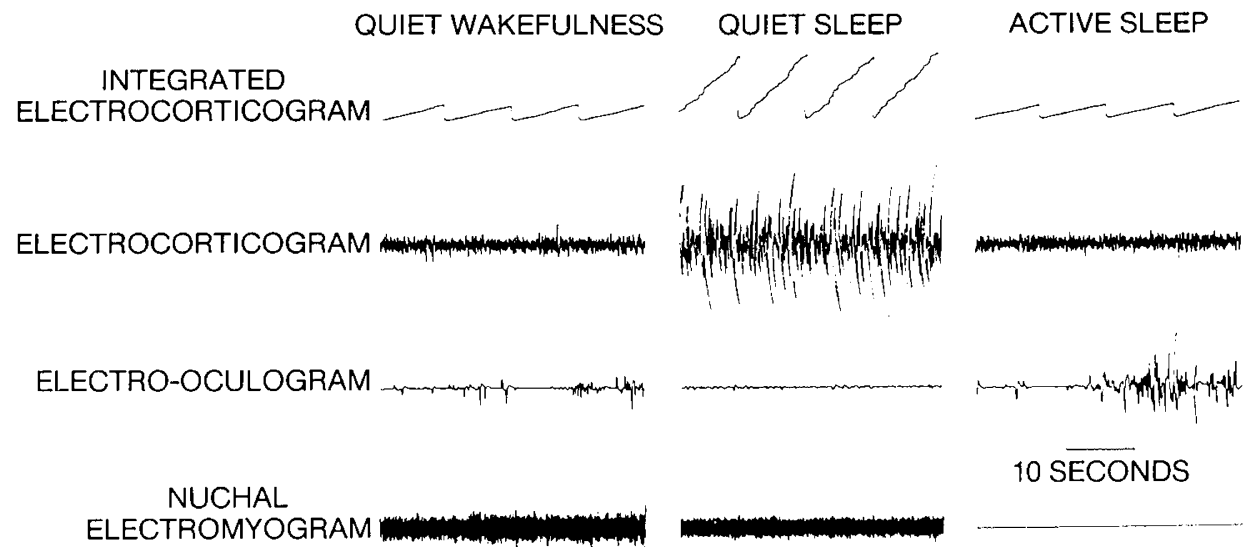

Fig. 2. Tracings showing electrophysiological recordings used to define behavioral state.

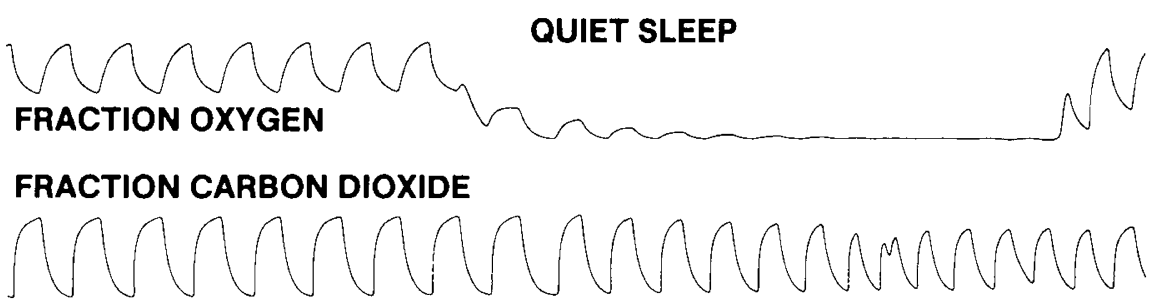

\section{ARTERIAL HEMOGLOBIN OXYGEN SATURATION}
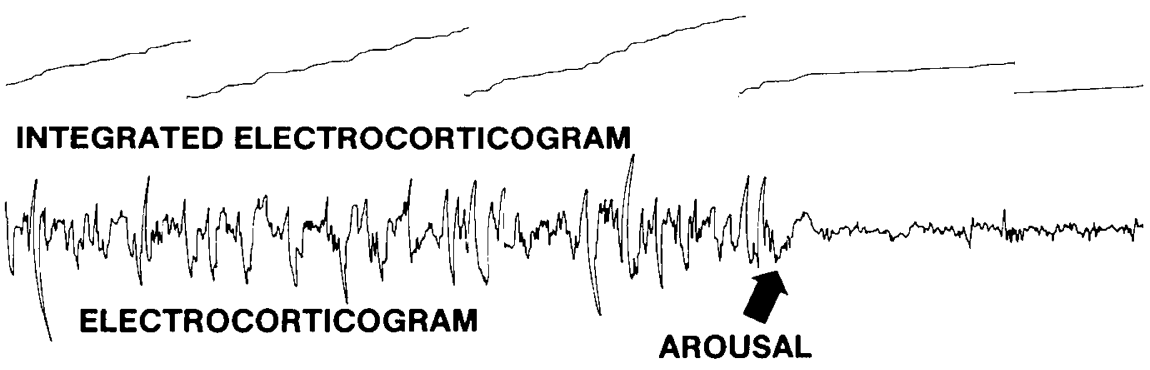

\section{ELECTRO-OCULOGRAM}

5 SECONDS

\section{NUCHAL ELECTROMYOGRAM}

Fig. 3. Electrophysiological criteria used to define arousal from quiet sleep. During quiet sleep, the point of arousal was determined by a change in the electrocorticogram from a high voltage-slow wave pattern to a low voltage-fast wave pattern.

or the cardiopulmonary changes prior to arousal (11). If there was a significant difference, a Newman-Keuls multiple range $t$ test was performed to determine which means were statistically different (12).

Hypothetical arousal responses. We reasoned that if arousal from sleep occurs at similar $\mathrm{SaO}_{2}$ despite the different rates of $\mathrm{SaO}_{2}$ that occur when breathing the different oxygen mixtures, that this would indicate that arousal occurs as soon as an arousal threshold had been reached. However, if arousal from sleep occurs at different $\mathrm{SaO}_{2}$ during the different rates of arterial hemoglobin oxygen desaturation, we believe that this would indicate that arousal occurs following an arousal latency once arousal threshold has been reached.

\section{RESULTS}

The rate of arterial hemoglobin oxygen desaturation that occurred when breathing either 0,5 , or $10 \%$ oxygen was not affected by sleep state (Figs. 5 and 6). However, the arousal response to rapidly developing hypoxemia was affected by sleep state (Table 1). During quiet sleep, arousal occurred at similar arterial hemoglobin oxygen saturations despite the different rates of arterial hemoglobin oxygen desaturation that occurred when the lambs were breathing the different oxygen mixtures. In contrast, during active sleep, arousal occurred at different $\mathrm{SaO}_{2}$ when the lambs were breathing the different oxygen mixtures. In active sleep, arousal was preceded by electrocortical signs of cerebral hypoxia (i.e. high voltage-slow waves) in three of 23 epochs on $5 \%$ oxygen in two lambs and in 10 of 23 epochs on $0 \%$ oxygen in six lambs (e.g. Fig. 7). The $\mathrm{SaO}_{2}$ during active sleep at which high voltage-slow waves appeared on the electrocorticogram was quite variable (average \pm 1 SD was $47 \pm 14 \%$; range was 30 to $63 \%$ ).

During rapidly developing hypoxemia before arousal or electrocortical signs of cerebral hypoxia, heart rate and blood pressure did not differ significantly from control values in either sleep state (Table 2 ). The lambs did respond to rapidly developing hypoxemia by increasing respiratory center output (Table 3 ). 


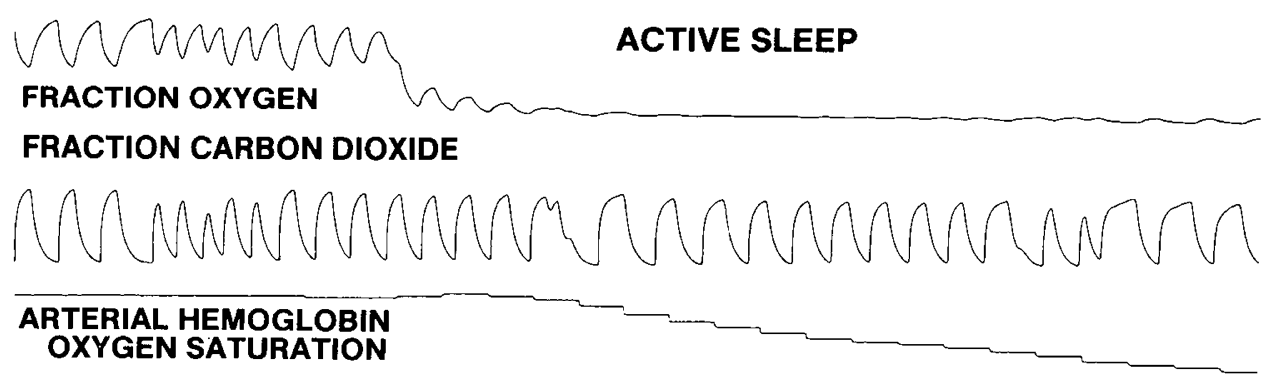

\section{INTEGRATED ELECTROCORTICOGRAM}

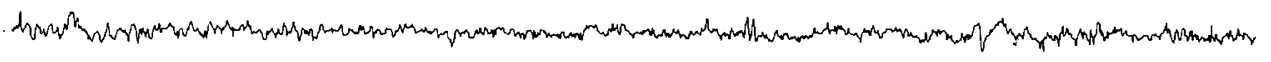

ELECTROCORTICOGRAM

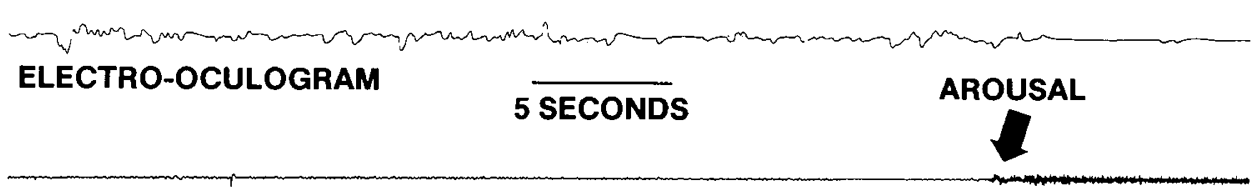

NUCHAL ELECTROMYOGRAM

Fig. 4. Electrophysiological criteria used to define arousal from active sleep. During active sleep, the point of arousal was determined by a return of tonic activity on the nuchal electromyogram.

QUIET SLEEP

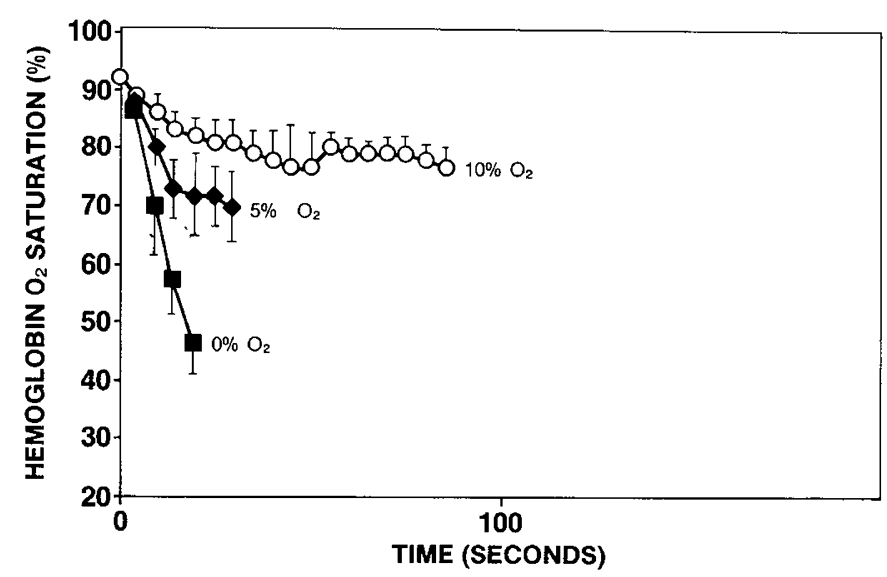

Fig. 5. $\mathrm{SaO}_{2}$ at 5 -s intervals in quiet sleep when the lambs were breathing either 10,5 , or $0 \%$ oxygen. Values are means \pm 1 SD for eight lambs.

Following the appearance of slow waves on the electrocorticogram, opisthotonus and primary apnea occurred in a number of epochs when the lambs were breathing $0 \%$ oxygen. Primary apnea was followed by gasping. Blood pressure tended to increase and the heart rate decreased following electrocortical signs of cerebral hypoxia, opisthotonus, and primary apnea (Fig. 7). All animals quickly recovered once they initiated gasping efforts since we increased the inspired oxygen concentration once slow waves appeared on the electrocorticogram.

\section{DISCUSSION}

Our study provides new information about the arousal response from sleep during rapidly developing hypoxemia in lambs. The data provide evidence that the $\mathrm{SaO}_{2}$ at arousal is dependent on the rate of change of the arterial oxygen in active sleep but not quiet sleep. Furthermore, if the rate of change of oxygen is great enough during active sleep, electrocortical signs

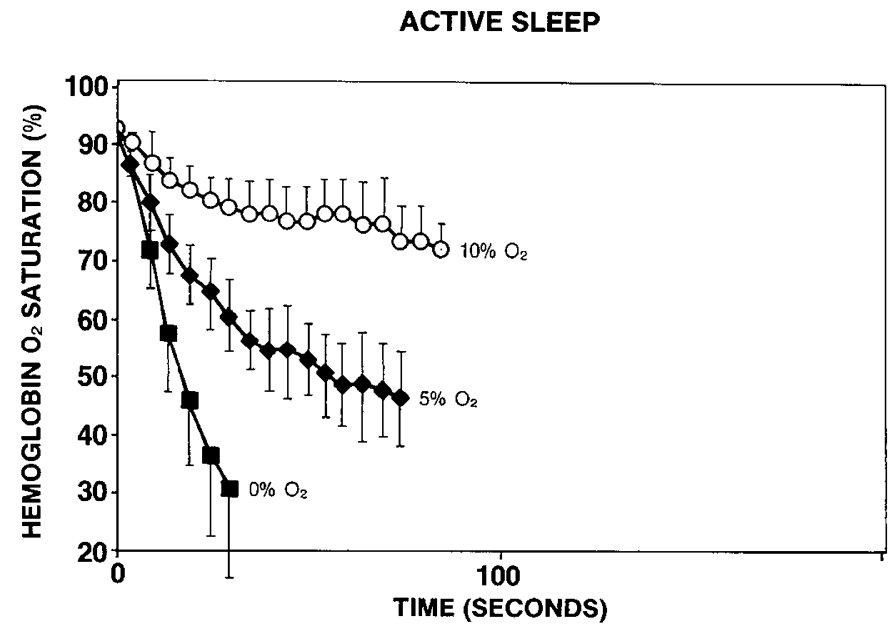

Fig. 6. $\mathrm{SaO}_{2}$ at 5-s intervals in active sleep when the lambs were breathing either 10,5 , or $0 \%$ oxygen. Values are means \pm 1 SD for eight lambs.

of cerebral hypoxia and primary apnea may actually precede arousal from sleep.

During quiet sleep, arousal occurred at similar $\mathrm{SaO}_{2}(81 \pm 6 \%$ on $10 \% \mathrm{O}_{2}, 80 \pm 5 \%$ on $5 \% \mathrm{O}_{2}$, and $83 \pm 5 \%$ on $0 \% \mathrm{O}_{2}$ ) despite the different rates of $\mathrm{SaO}_{2}$ that occurred when the lambs were breathing the different oxygen mixtures. This suggests that arousal occurred once an arousal threshold had been reached. However, during active sleep, arousal occurred at different $\mathrm{SaO}_{2}$ $\left(76 \pm 6 \%\right.$ on $10 \% \mathrm{O}_{2}, 55 \pm 11 \%$ on $5 \% \mathrm{O}_{2}$, and $44 \pm 17 \%$ on $0 \% \mathrm{O}_{2}$ ) when the lambs were breathing the different oxygen mixtures. This suggests that arousal occurred following an arousal latency once arousal threshold had been reached. The neurophysiological basis for this arousal latency in active sleep is presently unknown.

During some epochs of active sleep (i.e. three of 23 epochs on $5 \% \mathrm{O}_{2}$ in two lambs and 10 of 21 epochs on $0 \%$ in six lambs), the electrocorticogram changed from a fast wave-low voltage 
Table 1. Arousal response to rapidly developing hypoxemia in quiet sleep (QS) and active sleep (AS) in lambs*

\begin{tabular}{lcccll}
\hline & $\begin{array}{c}\text { No. epochs } \\
\text { aroused }\end{array}$ & $\begin{array}{c}\text { Time to } \\
\text { arousal }\end{array}$ & $\begin{array}{c}\text { Control } \\
\mathrm{O}_{2} \\
\text { saturation }\end{array}$ & $\begin{array}{l}\text { Saturation } \\
\text { at arousal }\end{array}$ \\
\hline QS-10\% $\mathrm{O}_{2}$ & $18 / 23$ & $35 \pm 33 \mathrm{~s}$ & $92 \pm 3 \%$ & $81 \pm 6 \%$ & $\mathrm{NS} \dagger$ \\
$\mathrm{QS}-5 \% \mathrm{O}_{2}$ & $25 / 25$ & $13 \pm 8 \mathrm{~s}$ & $92 \pm 4 \%$ & $80 \pm 5 \%$ & $\mathrm{NS} \ddagger$ \\
$\mathrm{QS}-0 \% \mathrm{O}_{2}$ & $22 / 22$ & $7 \pm 2 \mathrm{~s}$ & $92 \pm 4 \%$ & $83 \pm 5 \%$ & $\mathrm{NS} \S$ \\
$\mathrm{AS}-10 \% \mathrm{O}_{2}$ & $19 / 20$ & $56 \pm 22 \mathrm{~s}$ & $92 \pm 4 \%$ & $76 \pm 6 \%$ & $(0.005) \dagger$ \\
$\mathrm{AS}-5 \% \mathrm{O}_{2}$ & $20 / 23$ & $44 \pm 15 \mathrm{~s}$ & $91 \pm 4 \%$ & $55 \pm 11 \%$ & $(0.09) \ddagger$ \\
$\mathrm{AS}-0 \% \mathrm{O}_{2}$ & $11 / 21$ & $21 \pm 5 \mathrm{~s}$ & $92 \pm 4 \%$ & $44 \pm 17 \%$ & $(0.001) \S$ \\
\hline
\end{tabular}

* Data are means \pm 1 SD for $n=8$ in quiet sleep and $n=6$ in active sleep. Data are presented for only six of eight lambs in active sleep since electrocortical signs of cerebral hypoxia occurred on $0 \% \mathrm{O}_{2}$ before arousal from sleep during all epochs in two lambs.

$+10 \% \mathrm{O}_{2}$ versus $5 \% \mathrm{O}_{2}$.

$\ddagger 5 \% \mathrm{O}_{2}$ versus $0 \% \mathrm{O}_{2}$.

$\S 10 \% \mathrm{O}_{2}$ versus $0 \% \mathrm{O}_{2}$ for saturation at arousal. Arousal did not occur within 2 min in five epochs of quiet sleep and one epoch of active sleep on $10 \%$ oxygen. In active sleep, arousal did not occur before electrocortical signs of cerebral hypoxia occurred in three of 23 epochs on $5 \% \mathrm{O}_{2}$ in two lambs and 10 of 21 epochs on $0 \% \mathrm{O}_{2}$ in six lambs. Primary apnea usually followed signs of cerebral hypoxia on $0 \% \mathrm{O}_{2}$.
Table 2. Lack of significant effect of rapidly developing hypoxemia on heart rate and blood pressure during quiet sleep $(Q S)$ and active sleep (AS) in lambs*

\begin{tabular}{|c|c|c|c|c|}
\hline & \multicolumn{2}{|c|}{ Heart rate $(\mathrm{bpm})$} & \multicolumn{2}{|c|}{$\begin{array}{l}\text { Blood pressure } \\
(\mathrm{mm} \mathrm{Hg})\end{array}$} \\
\hline & Control & Arousal & Control & Arousal \\
\hline QS- $10 \% \mathrm{O}_{2}$ & $158 \pm 25$ & $167 \pm 13$ & $\begin{array}{l}83 \pm 13 \\
58 \pm 6\end{array}$ & $\begin{array}{l}87 \pm 14 \\
59 \pm 8\end{array}$ \\
\hline QS-5\% $\mathrm{O}_{2}$ & $162 \pm 22$ & $174 \pm 28$ & $\begin{array}{l}82 \pm 9 \\
56 \pm 5\end{array}$ & $\begin{array}{l}86 \pm 11 \\
60 \pm 8\end{array}$ \\
\hline QS- $-0 \% \mathrm{O}_{2}$ & $169 \pm 29$ & $184 \pm 40$ & $\begin{array}{l}81 \pm 9 \\
55 \pm 7\end{array}$ & $\begin{array}{l}84 \pm 9 \\
59 \pm 9\end{array}$ \\
\hline $\mathrm{AS}-10 \% \mathrm{O}_{2}$ & $136 \pm 16$ & $156 \pm 16$ & $\begin{array}{l}78 \pm 12 \\
50 \pm 10\end{array}$ & $\begin{array}{l}80 \pm 10 \\
53 \pm 7\end{array}$ \\
\hline As $-5 \% \mathrm{O}_{2}$ & $153 \pm 25$ & $146 \pm 23$ & $\begin{array}{l}73 \pm 13 \\
48 \pm 14\end{array}$ & $\begin{array}{l}83 \pm 9 \\
51 \pm 7\end{array}$ \\
\hline AS $-0 \% \mathrm{O}_{2}$ & $149 \pm 21$ & $121 \pm 48$ & $\begin{array}{l}86 \pm 19 \\
55 \pm 18\end{array}$ & $\begin{array}{l}83 \pm 7 \\
47 \pm 7\end{array}$ \\
\hline
\end{tabular}

* Values are means \pm 1 SD for $n=8$ in quiet sleep and $n=6$ in active sleep. Blood pressure values are systolic/diastolic. There were no statistically significant changes in heart rate or blood pressure before arousal or electrocortical signs of cerebral hypoxia in either sleep state.
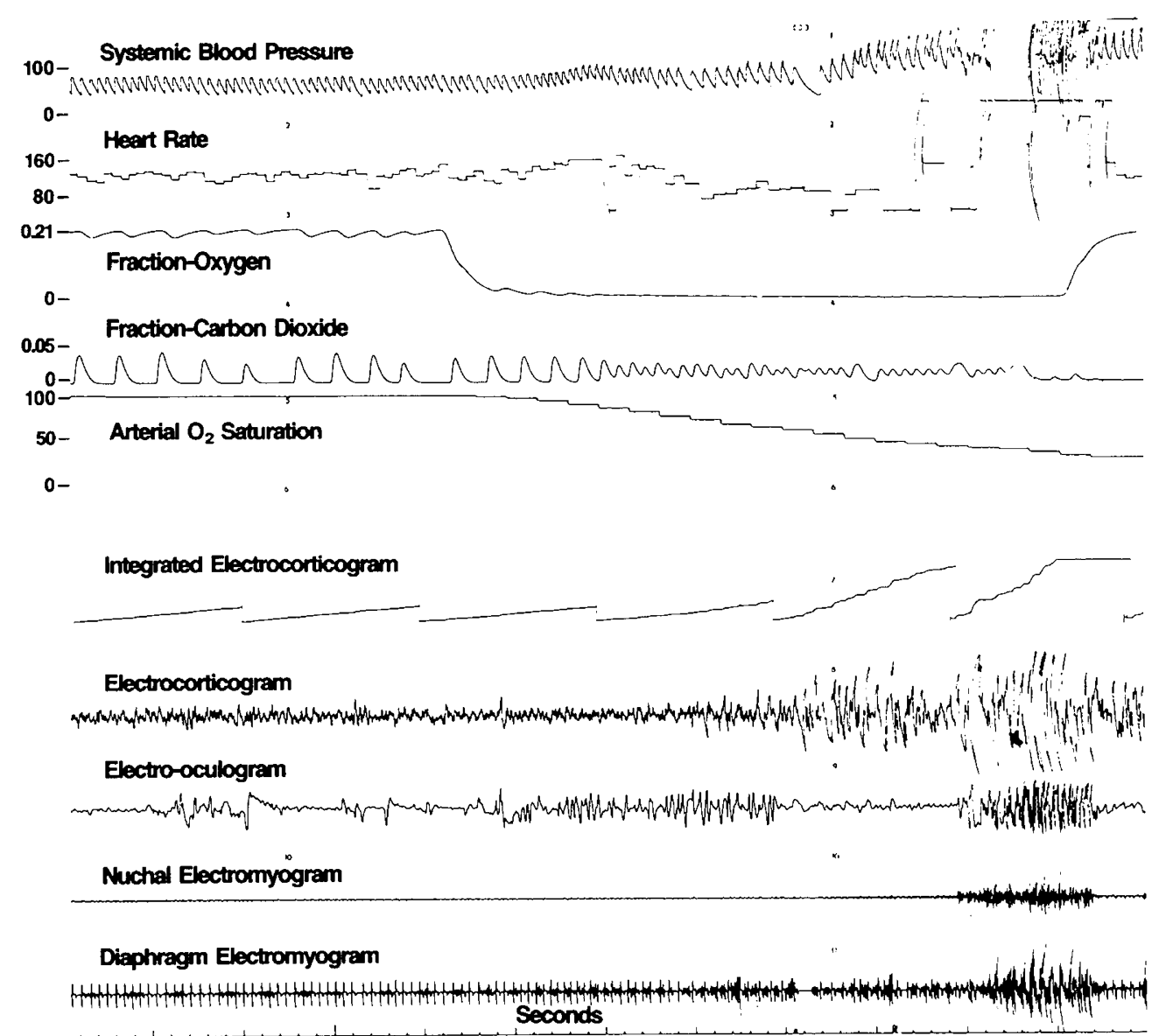

Fig. 7. Tracings showing physiological variables during inhalation of $0 \%$ oxygen in epoch of active sleep where lamb 437 did not rouse before electrocortical signs of cerebral hypoxia (i.e. high voltage slow waves) occurred. Following the onset of electrocortical high voltage slow waves, increased activity on the electrooculogram, nuchal electromyogram, and diaphragm electromyogram occurred during opisthotonus; primary apnea occurred during and following opisthotonus. The diagnosis of primary apnea was primarily based on the respired $\mathrm{CO}_{2}$ tracing, behavioral observations, and an audio signal generated from the diaphragm electromyogram. The diaphragm electromyogram tracing was usually of little help since primary apnea usually occurred following opisthotonus and thus the appearance of tonic activity on the electromyograms. There was approximately a 3-s delay in the respired $\mathrm{CO}_{2}$ tracing compared to the diaphragm electromyogram. This is because of the dead space in the tubing leading from the proximal airway to the $\mathrm{CO}_{2}$ analyzer. 
Table 3. Effects of rapidly developing hypoxemia on respiratory frequency and integrated diaphragm electrical activity during quiet sleep $(Q S)$ and active sleep $(A S)$ in lambs*

\begin{tabular}{|c|c|c|c|}
\hline & \multicolumn{2}{|c|}{ Respiratory frequency } & \multirow{2}{*}{$\begin{array}{c}\begin{array}{c}\text { Integrated diaphragm } \\
\text { electrical activity }\end{array} \\
\begin{array}{c}\text { change from control } \\
\text { before arousal }\end{array} \\
\end{array}$} \\
\hline & Control & Arousal & \\
\hline $\begin{array}{l}\text { QS-10\% O } \\
\text { QS-5\% O } \\
\text { QS- }-0 \% \mathrm{O}_{2} \\
\text { AS-10\% } \mathrm{O}_{2} \\
\text { AS-5\% O } \\
\text { AS- } 0 \mathrm{O}_{2}\end{array}$ & $\begin{array}{l}30 \pm 12(0.04) \dagger \\
29 \pm 11(0.001) \dagger \\
31 \pm 11(0.001) \dagger \\
37 \pm 10 \mathrm{NS} \dagger \\
40 \pm 10(0.02) \dagger \\
44 \pm 18(0.02) \dagger\end{array}$ & $\begin{array}{l}39 \pm 14 \mathrm{NS} \ddagger \\
44 \pm 19 \mathrm{NS} \S \\
48 \pm 22(0.001) \| \\
37 \pm 10(0.009) \ddagger \\
56 \pm 11 \mathrm{NS} \S \\
55 \pm 19(0.013) \|\end{array}$ & $\begin{array}{l}+23 \pm 18 \%(0.05) \ddagger \\
+81 \pm 45 \% \mathrm{NS} \S \\
+90 \pm 51 \%(0.009) \| \\
+30 \pm 17 \%(0.02) \ddagger \\
+128 \pm 83 \% \mathrm{NS} \S \\
+92 \pm 41 \%(0.05) \|\end{array}$ \\
\hline
\end{tabular}

* Values are means \pm 1 SD for $n=8$ in quiet sleep and $n=6$ in active sleep.

$\dagger$ Control versus arousal.

$\$ 10 \% \mathrm{O}_{2}$ versus $5 \% \mathrm{O}_{2}$.

$\S 5 \% \mathrm{O}_{2}$ versus $0 \% \mathrm{O}_{2}$.

$\| 10 \% \mathrm{O}_{2}$ versus $0 \% \mathrm{O}_{2}$.

pattern to a slow wave-high voltage pattern before the animal aroused. Similar changes on the electroencephalogram have been documented in children during long breatholding spells $(13,14)$ and in infants during severe expiratory apnea (15). The slow waves observed in our study were probably secondary to cerebral hypoxia (16). In the cat, similar cortical changes occur during hypoxia and coincide with the disappearance of the electrical activity of cortical neurons as recorded by microelectrodes (17). Early experiments by Noell and Dombrowski (18) and by Ward (19) suggest during this phase of cortical electrical silence produced by hypoxia, that 1) slow waves are recorded from the whole of the diencepahalon and mesencephalon which are functionless, 2) that normal rhythms are present only in the rhombencephalic reticular formation which continues to function and, 3 ) that the activity of the reticular formation, uncontrolled by upper levels, initiates a transitory hypertonia by "liberation" of its excitatory neurones to muscle tone. This is most likely the explanation for the tonic posturing with the neck and back arched and the extremities extended (i.e. opisthotonus) we observed after the appearance of slow waves on the electrocorticogram (Fig. 7) during several epochs of active sleep on $0 \%$ oxygen.

Previous investigations of the arousal response from sleep to rapidly developing hypoxemia in newborns $(5,6)$ have not separated arousal threshold required to cause arousal from the latency to arousal once arousal threshold has been reached. Henderson-Smart and Read (5) investigated the arousal response to rapidly developing hypoxemia in newborn lambs and found that in quiet sleep the range of $\mathrm{SaO}_{2}$ at the termination of eight tests was $66-83 \%$ (mean $74 \%$ ) and arousal occurred on six occasions. In active sleep, arousal occurred in only two of eight tests despite lower $\mathrm{SaO}_{2}$ (range $45-58 \%$, mean $50 \%$ ). Jeffery and Read (6) investigated the arousal response to rapidly developing hypoxemia in newborn calves and found that arousal occurred during all tests and at arterial hemoglobin oxygen saturations of $84.9 \pm 2.3 \%$ (mean $\pm 1 \mathrm{SD}$ ) in quiet sleep and $59.2 \pm 6.8 \%$ in active sleep. The difference in the results of the arousal tests in lambs and calves, particularly in active sleep, may be related to species differences. However, it may also be related to the fact that the lambs rebreathed $0 \%$ from a bag which decreased the $\mathrm{SaO}_{2}$ at a rate of $2-3 \%$ per s, whereas the calves rebreathed 8 $10 \%$ oxygen from a bag which decreased the $\mathrm{SaO}_{2}$ to $50 \%$ over a period of $90 \mathrm{~s}$. The fact that arousal from sleep in response to rapidly developing hypoxemia occurs at a lower $\mathrm{SaO}_{2}$ during active sleep than during quiet sleep may be explained by the effect of sleep state on the latency to arousal once arousal threshold has been reached just as well as the effect of sleep state on the arousal threshold, or perhaps it is a combination of the two.

The arousal resonse from sleep has been suggested to be an important protective response that may prevent severe hypoxemia and death during an apneic episode (1). Although apnea occurs to some extent in almost all preterm (20) and term infants (21), little is known about the mechanism that terminates an apneic episode. Read and Henderson-Smart (20) have observed that prolonged apnea (i.e. apnea of $20 \mathrm{~s}$ or longer) occurs in the majority of babies under $30 \mathrm{wk}$ gestation, in about $50 \%$ of babies at 30-32 wk gestation, and in about 7\% of babies at 34-35 wk gestation. Furthermore, Southall et al. (21) presented data showing that 34 of 50 (i.e. $68 \%$ ) randomly selected, healthy term infants studied between 1 and 15 days postnatally had apneic episodes of $10 \mathrm{~s}$ or longer and that the 95 th percentile extended up to $18 \mathrm{~s}$. Guntheroth (22) has suggested that these infants do not die because of an intact arousal response and has hypothesized that the crucial area of abnormal physiology in SIDS is arousal after apnea. The importance of the arousal response is at least two-fold. First, wakefulness per se is a potent stimulus to breathing. Second, arousal permits the initiation of behavioral and ventilatory response to the stimulus; arousal is generally thought to precede resumption of tidal ventilation during apnea $(7-10)$.

Two recent studies have provided evidence of an abnormal arousal response to hypoxemia in infants who have had an ALTE $(23,24)$. McCulloch et al. (23) found that only one of 11 ALTE infants aroused in response to progressive alveolar hypoxia $\left(\mathrm{FIO}_{2}\right.$ $0.15)$ compared to 14 of 22 normal infants. Following this study, it was suggested that the lack of an arousal response in $30 \%$ of the control infants was due to lack of maximal chemoreceptor stimulation (24). Subsequently, van der Hal (24) found that nine of nine control infants aroused in response to more pronounced alveolar hypoxia $\left(\mathrm{FIO}_{2} 0.11\right)$ compared to only 19 of 50 ALTE infants. These data support the hypothesis that an abnormal arousal response to hypoxemia may play a role in the final pathway to the SIDS.

The respiratory response of both newborn (25-27) and adult (28) animals to progressive hypoxemia has been shown to pass through four stages: hyperpnea, primary apnea, gasping, and terminal apnea. Our animals did respond to rapidly developing hypoxemia by increasing respiratory center output. During quiet sleep, there was a consistent increase in respiratory frequency and integrated diaphragm electromyographic activity which most likely produced an increase in minute ventilation. However, the increase in respiratory center output may not produce the same end result in active sleep as inspiratory rib cage collapse occurs in this species during active sleep (5). Primary apnea occurred with or just following opisthotonus during several epochs of active sleep on $0 \% \mathrm{O}_{2}$. However, all animals quickly recovered once they initiated gasping efforts since we increased the inspired oxygen concentration once slow waves appeared on the electro- 
corticogram. It has previously been suggested that animals can easily "autoresuscitate" themselves during primary apnea by gasping if an adequate circulation has been maintained $(28,29)$. The ability of the myocardium to tolerate hypoxia appears to be important; if the circulation ceases, a gasp will have no benefit without the transport of oxygen to vital organs such as the heart and brain. We found that all of our animals maintained blood pressure at or above control level in response to rapidly developing hypoxemia.

The results of this study may have implications for SIDS. If the final event is apnea, as has been hypothesized $(22,30)$, our data would allow one to speculate that if the rate of change of arterial oxygen is great enough during apnea in active sleep, arousal may fail to occur before electrocortical signs of cerebral hypoxia and primary apnea occur. If in addition there is a deficit in the gasping mechanism or if the circulation fails prior to the onset of gasping, death could quickly ensue. In this regard, it is most interesting that Stevens (31) noted that "the stomach contents were observed on occasions to well into the pharynx" in infants during severe apneic episodes following the onset of opisthotonos. Whether or not this would result in stimulation of larygneal chemoreceptors with subsequent alteration of the gasping response is not known.

If our speculation is correct, then any factor that tends to accentuate the rate of $\mathrm{SaO}_{2}$ and thus, decrease the supply of oxygen to the tissues during cessation of air flow such as decreased lung oxygen stores [e.g. chronic lung disease, active sleep (32)] or a decreased oxygen-carrying capacity of the blood [e.g. anemia (33)] would have a deleterious effect. In a similar fashion, any factor that would tend to increase the metabolic oxygen consumption (e.g. cool environmental temperature (34), fever, or perhaps even feeding (35)] would also have a deleterious effect.

\section{REFERENCES}

1. Phillipson EA, Sullivan CE 1978 Arousal: The forgotten response to respiratory stimuli. Am Rev Respir Dis 118:807-809

2. Muller NL, Francis PW, Gurwitz D, Levison H, Bryan AC 1980 Mechanism of hemoglobin desaturation during rapid-eye-movement sleep in normal subjects and in patients with cystic fibrosis. Am Rev Respir Dis 121:463469

3. Taussig LM: Long-term management and pulmonary prognosis in bronchopulmonary dysplasia. In: Farrell PM, Taussig LM (eds) Bronchopulmonary Dysplasia and Related Chronic Disorders. Ross Laboratories, Columbus, $\mathrm{OH}, \mathrm{pp} 126-135$

4. Hudgel DW, Kellum R, Martin RJ, Johnson B 1982 Depressed arousal response to airflow obstruction-a possible factor in near fatal nocturnal asthma. Am Rev Respir Dis 125:202

5. Henderson-Smart DJ, Read DJC 1979 Ventilatory responses to hypoxemia during sleep in the newborn. J Dev Physiol 1:195-208

6. Jeffery HE, Read DJC 1980 Ventilatory responses of newborn calves to progressive hypoxia in quiet and active sleep. J Appl Physiol 48:892-895

7. Gastaut H, Tassinari CA, Duron B 1966 Polygraphic study of the episodic diurnal and nocturnal (hypnic and respiratory) manifestations of the Pickwickian syndrome. Brain Res 2:167-186

8. Walsh RE, Michealson ED, Harkerload LE, Zichelboim A, Sackner MA 1972
Upper airway obstruction in obese patients with sleep disturbances and somnolence. Ann Intern Med 76:185-192

9. Remmers JE, DeGroot WJ, Sauerland EK, Anch AM 1978 Pathogenesis of upper airway occlusion during sleep. J Appl Physiol 44:931-938

10. Frank Y, Kravath RE, Pollack CP, Weitzman ED 1983 Obstructive sleep apnea and its therapy: clinical and polysomnographic manifestations. Pediatrics $71: 737-740$

11. Winer BJ 1971 Single-factor experiments having repeated measures on the same elements. In: Statistical Principles in Experimental Design. McGrawHill Book Company, New York, pp 261-308

12. Zar JH 1979 Multiple Comparisons In: Biostistical Analyses. Prentice-Hall, Englewood Cliffs, NJ, pp 15!-162

13. Gauk EW, Kidd L, Prichard JS 1963 Mechanisms of seizures associated with breath-holding spells. N Engl J Med 286:1436-1441

14. Lombroso CT, Lerman P 1967 Breathholding spells (cyanotic and pallid infantile syncope). Pediatrics 39:563-581

15. Southall DP, Johnson P, Salmons S, Talbert DG, Morley CJ, Miller J, Helms PJ 1985 Prolonged expiratory apnoea: a disorder resulting in episodes of severe arterial hypoxaemia in infants and young children. Lancet $2: 571-577$

16. Gastaut H, Gastaut Y 1958 Electroencephalographic and clinical study of anoxic convulsions in children. Electroencephalogr Clin Neurophysiol 10:607-620

17. Kasamatsu A, Saito Y, Endo S, Koga D 1956 Single cortical unit discharge under hypoxia. Folia Psychiat Neurol Jap 3 (suppl):8-9

18. Noell WK, Dombrowski EB 1947 Cerebral localization and classification of convulsions produced by a severe oxygen lack. School of Aviation Medicine Randolph Field, TX, Project 497, p 13

19. Ward AA 1947 Decerebrate rigidity. J Neurophysiol 10:89-103

20. Read DJC. Henderson-Smart DJ 1984 Regulation of breathing in the newborn during different behavioral states. Ann Rev Physiol 46:675-685

21. Southall DP, Richards J, Brown DJ, Johnston PGB, DeSwiet M, Shinebourne EA 1980 24-Hour recordings of ECG and respiration in the newborn infant with findings related to sudden death and unexplained brain damage in infancy. Arch Dis Child 55:7-16

22. Guntheroth WG 1983 Arrhythmia, apnea or arousal? In: Tildon WT, Rolder LM, Steinschneider A (eds) Sudden Infant Death Syndrome. Academic Press, London, pp 263-269

23. McCulloch K, Brouillette RT, Guzzetta AJ, Hunt CE 1982 Arousal response in near-miss sudden infant death syndrome and in normal infants. J Pediatr 101:911-917

24. van der Hal AL, Rodriguez AM, Sargent CW, Platzker ACG, Keens TG 1985 Hypoxic and hypercapneic arousal responses and prediction of subsequent apnea in apnea of infancy. Pediatrics 75:848-854

25. Davis JA 1961 The effect of anoxia in new-born rabbits. J Physiol 155:56P

26. Godrey S 1968 Respiratory and cardiovascular changes during asphyxia and resuscitation of foetal and newborn rabbits. Q J Exp Physiol 53:97-118

27. Lawson EE, Thach BT 1977 Respiratory patterns during progressive asphyxia in newborn rabbits. J Appl Physiol 43:468-474

28. Guntheroth WG, Kawabori I 1975 Hypoxic apnea and gasping. J Clin Invest $56: 1371-1377$

29. Dawes GS 1968 Foetal and Neonatal Physiology: A Comparative Study of the Changes at Birth. Year Book Medical Publishers, Inc, Chicago

30. Steinschneider A 1972 Prolonged apnea and the sudden infant death syndrome clinical and laboratory observations. Pediatrics 50:646-654

31. Stevens LH 1965 Sudden unexplained death in infancy. Am J Dis Child 110:243-247

32. Henderson-Smart DJ, Read DJC 1979 Reduced lung volume during behavioral active sleep in the newborn. J Appl Physiol 46:1081-1085

33. Wardrop CAJ, Holland BM, Veale KEA, Jones JG, Gray OP 1978 Nonphysiological anemia of prematurity. Arch Dis Child 53:855-860

34. Sidi D, Kuipers JRG, Heymann MA, Rudolph AM 1983 Effects of ambient temperature on oxygen consumption and the circulation in newborn lambs at rest and during hypoxemia. Pediatr Res 17:254-258

35. Zwillich CW, Sahn SA, Weil JV 1977 Effects of hypermetabolism on ventilation and chemosensitivity. J Clin Invest 60:900-906 